\title{
CASE STUDY ON MULTI-DRUG RESISTANCE TUBERCULOSIS IN GROBOGAN, CENTRAL JAVA
}

\author{
Gunawan Cahyo Utomo' ${ }^{1)}$, Hermanu Joebagyo²), Bhisma Murti1 ${ }^{1)}$ \\ 1) Masters Program in Public Health, Sebelas Maret University \\ 2)Faculty of Teaching and Educational Sciences, Sebelas Maret University
}

\begin{abstract}
Background: Tuberculosis is a communicable disease that remains a major public health issue worldwide. Tuberculosis epidemics have become a primary public health concern for the last few decades. The problem becomes aggrevated due to the emergence of Multiple Drugs Resistant Tuberculosis (MDR-TB). It is estimated there are 6,100 MDR-TB cases annually in Indonesia. Grobogan is one of the 6 districts in ex-residential Pati in Central Java with the second highest MDR-TB cases after Kudus. Between 2011 and 2016 the annual incidence was 23 cases with case fatality rate of $52.17 \%$. This study aimed to investigate the different roles of MDR-TB patients, families, TB progammers, and health providers, in the incidence of MDR-TB in Grobogan, Central Java

Subjects and Method: This was an analytic qualitative study with case study approach. The study was conducted in Grobogan, Central Java, from May to June 2017. A total of 26 informants were selected purposively for this study, consisting of 7 MDR-TB patients, 7 family members who served as drug-taking supervisor, 7 TB programmers at Community Health Centers, 1 TB programmer at District Hospital, 3 Community Health Center doctors, and 1 District Hospital doctor. The data were collected by in-depth interview, direct observation, and document review. Interactive analysis was used to analyze data, including data collection, reduction, presentation, and verification.
\end{abstract}

Results: All MDR-TB patients had favorable perceived susceptibility, perceived severity, and self-efficacy, that drove them to adhere to TB treatment. Most patients reported that the treatment was beneficial. The existing barrier was not of serious concern that made them to stop treatment.

Families of the patients had positive attitude towards TB treatment so they provided the necessary support in acessing treatment and adherence to treatment. However, TB program management at District Hospital, was suboptimal as it did not administer appropriately the standard DOTS-TB treatment guideline, despite the existence of TB standard operating procedure. Likewise, TB treatment management by hospital doctors and private practice doctors was inadequate, due to the lack of DOTS-TB training. The lack of adherence in implementing the standard DOTS-TB treatment guideline was the dominant causal factor for the incidence of MDR-TB in Grobogan district, Central Java.

Conclusion: Adequate DOTS-TB treatment management and quality health services at both primary and secondary level facilities are needed in the efforts to prevent MDR TB. It is suggested that the government through the District Health Office hold DOTS-TB promotion program and invest in developing skilled DOTSTB providers.

Keywords: multidrug resistance, tuberculosis, TB management program, adherence

Correspondence: Gunawan Cahyo Utomo. Masters Program in Public Health, Sebelas Maret University, Jl. Ir. Sutami 36A, Surakarta 57126, Central Java. Email: abuzahra_o6@yahoo.com. Mobile: +6281390046456. 